\title{
Current characteristics and management of ST elevation and non-ST elevation myocardial infarction in the Tokyo metropolitan area: from the Tokyo CCU network registered cohort
}

\author{
Hideki Miyachi $^{1,2} \cdot$ Atsushi Takagi $^{1} \cdot$ Katsumi Miyauchi $^{1} \cdot$ Masao Yamasaki $^{1} \cdot$ \\ Hiroyuki Tanaka ${ }^{1}$ Masatomo Yoshikawa ${ }^{1} \cdot$ Mike Saji $^{1} \cdot$ Makoto Suzuki $^{1}$ • \\ Takeshi Yamamoto $^{1} \cdot$ Wataru Shimizu $^{3} \cdot \operatorname{Ken~Nagao}^{1} \cdot$ Morimasa Takayama $^{1}$ \\ Received: 25 September 2015 / Accepted: 25 December 2015 / Published online: 12 January 2016 \\ (C) The Author(s) 2016. This article is published with open access at Springerlink.com
}

\begin{abstract}
Limited data exists on ST-segment elevation myocardial infarction (STEMI) and non-STEMI (NSTEMI) managed by a well-organized cardiac care network in a metropolitan area. We analyzed the Tokyo CCU network database in 2009-2010. Of 4329 acute myocardial infarction (AMI) patients including STEMI $(n=3202)$ and NSTEMI $(n=1127)$, percutaneous coronary intervention (PCI) was performed in $88.8 \%$ of STEMI and $70.4 \%$ of NSTEMI patients. Mean onset-to-door and door-to-balloon times in STEMI patients were shorter than those in NSTEMI patients (167 vs 233 and 60 vs $145 \mathrm{~min}$, respectively, $p<0.001)$. Coronary artery bypass graft surgery was performed in $4.2 \%$ of STEMI and $11.4 \%$ of NSTEMI patients. In-hospital mortality was significantly higher in STEMI patients than NSTEMI patients (7.7 vs $5.1 \%$, $p<0.007)$. Independent correlates of in-hospital mortality were advanced age, low blood pressure, and high Killip classification, statin-treated dyslipidemia and PCI within $24 \mathrm{~h}$ were favorable predictors for STEMI. High Killip classification, high heart rate, and hemodialysis were significant predictors of in-hospital mortality, whereas statin-treated dyslipidemia was the only favorable predictor for NSTEMI. In conclusion, patients with MI received PCI frequently $(83.5 \%)$ and promptly (door-to-balloon time; $66 \mathrm{~min}$ ), and had favorable in-hospital prognosis
\end{abstract}

Hideki Miyachi

hidep-@nms.ac.jp

1 Tokyo CCU Network Scientific Committee, Tokyo, Japan

2 Division of Cardiovascular Intensive Care, Nippon Medical School Hospital, 1-1-5 Sendagi, Bunkyo-ku, Tokyo 113-8603, Japan

3 Department of Cardiovascular Medicine, Nippon Medical School, Tokyo, Japan (in-hospital mortality; $7.0 \%$ ). In addition to traditional predictors of in-hospital death, statin-treated dyslipidemia was a favorable predictor of in-hospital mortality for STEMI and NSTEMI patients, whereas hemodialysis was the strongest predictor for NSTEMI patients.

Keywords ST elevation myocardial infarction - Non-ST elevation myocardial infarction · In-hospital mortality · Risk factors

\section{Introduction}

Acute myocardial infarction (AMI) is a major cause of morbidity and mortality worldwide. The direct relationship between higher survival rates of ST elevation myocardial infarction (STEMI) patients and the earlier primary PCI can be performed has been well established [1, 2]. Current updated guidelines for non-STEMI (NSTEMI) in Japan, US, and Europe recommend an early invasive strategy within 24-h for high-risk patients defined as a GRACE score of $>140$ [3, 4]. However, little data regarding NSTEMI time courses is available in Japan.

The Tokyo CCU network is a well-organized cardiac care network. All 67 hospitals participating in the Tokyo CCU network have as a goal to perform emergency PCI within $1 \mathrm{~h}$ from arrival at the hospital. Deducing from the regional distribution of these 67 hospitals, the Tokyo CCU network probably includes $95 \%$ of all patients who had an AMI within the greater Tokyo area, moreover there are 13 million people in the Tokyo metropolitan area. Furthermore, gathering data from this cardiac care network on the current practices and in-hospital survival rates is vital to better serve the highly populated Tokyo metropolitan area. 


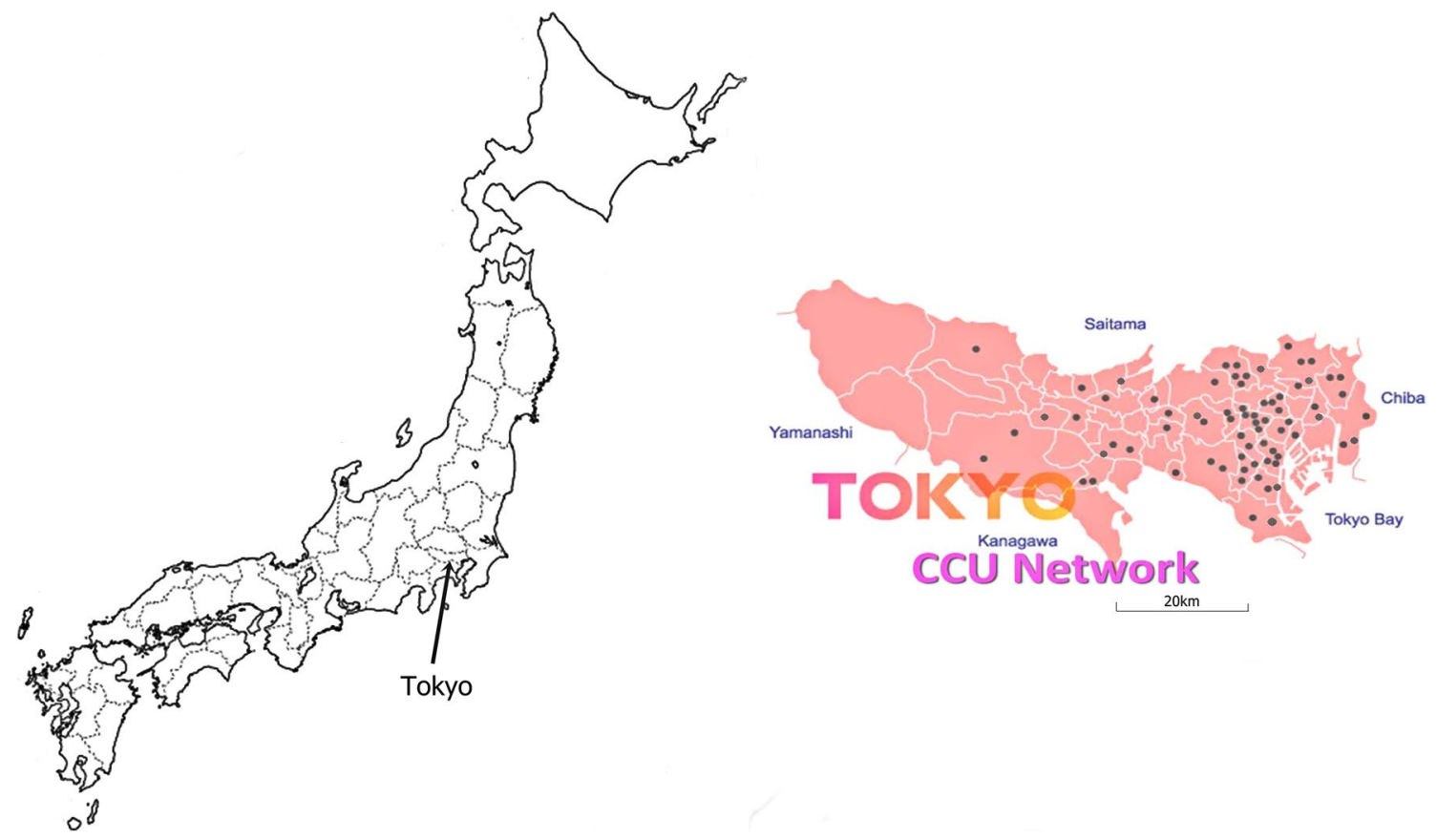

Fig. 1 Japanese and Tokyo map. This map shows the regional distribution of 67 hospitals participating in Tokyo CCU network

The aim of the present study was to clarify current characteristics, managements, time courses, and in-hospital outcomes in STEMI and NSTEMI patients in the Tokyo CCU network registered cohort within the contemporary realworld setting.

\section{Methods}

\section{The Tokyo CCU network registry}

The Tokyo CCU network was established in 1978 with the goal to treats patients with emergency cardiovascular events as promptly as possible, with the help of ambulance units dispatched through the Tokyo Fire Department [5]. The Tokyo CCU network database is an continually ongoing multicenter registry that prospectively collects information regarding emergency admissions to acute care facilities [6, 7]. The Tokyo CCU network was originally comprised of 12 major participating hospitals in 1978. Today it is comprised of 67 hospitals, serving a population of 13 million in the Tokyo metropolitan area (Fig. 1). Because all data is anonymously catalogued, informed consents are not required. In accordance with rules set forth by the Ministry of Internal Affairs and Communications, patient data collection policies are displayed at the emergency entrance of each individual Tokyo CCU network institution. The registry's purpose and mission are displayed on pamphlets, which also explain CCU personal information protections to emergency admission patients and their families. Data collection was performed via individual chart review by trained data collection personnel. The quality of submitted data is maintained through annual data quality checks which include point-of-entry mechanistic controls. No extramural funding was used to support this work. Each Tokyo CCU network hospital is accredited by the Metropolitan Tokyo Government and participates in the Tokyo citywide system of acute cardiac care (acute myocardial infarction, unstable angina, arrhythmia, acute heart failure, aortic dissection, and pulmonary embolism).

\section{Patients and data collection}

This study was performed using Tokyo CCU network registered cohort data collected from January 2009 to December 2010. Only the data of patients with AMI were selected. Clinical diagnoses of STEMI and NSTEMI, based on the 2007 universal definition, was made by individual cardiologists at Tokyo CCU network institutions [8]. All patients were prospectively registered at admission. For this study, STEMI and NSTEMI were redefined as the follow; STEMI, patients must have had chest symptoms, ST-segment elevation in 2 contiguous leads or left bundle branch block, and an elevated biochemical marker of myocardial necrosis 
(troponin $\mathrm{T}>0.1 \mathrm{ng} / \mathrm{ml}$ or creatine phosphokinase twofold the upper limit of normal); NSTEMI, patients must have had chest symptoms, ST-segment depression or T-wave inversion in 2 contiguous leads, and an elevated biochemical marker of myocardial necrosis. AMI patients that did not fulfill either definition in present study were excluded. The therapeutic strategies of STEMI and NSTEMI depended on the practice of each individual institution and individual cardiologist. However, all patients were treated based on guidelines set forth by the Japanese Circulation Society and ACC/AHA for the diagnosis and treatment of AMI $[2,3]$.

Clinical course information, as well as the diagnostic and therapeutic management of patients entering the registry, was obtained by means of a standardized questionnaire made by the steering committee. The following data was collected on patients with STEMI and NSTEMI: (1) time courses from onset of symptoms to admission to cardiovascular care unit and coronary revascularization; (2) patients' demographics, presenting characteristics, personal and/or family history of cardiovascular disease, and cardiovascular risk factors; (3) cardiovascular treatments during the hospitalization; (4) in-hospital all-cause death. Completed case report forms were checked by the Tokyo CCU network scientific committee for the validity and consistency of the data compiled.

For this study, 5291 consecutive patients were identified that satisfied STEMI and NSTEMI definition. However, data from 962 patients was incomplete and those cases were excluded from the analysis. Therefore data from the remaining 4329 patients were analyzed.

\section{Statistical analysis}

Categorical variables were tested using the Chi-square test or, if not applicable, Fisher's exact test. Continuous variables are presented as means and standard deviations and were tested using the Student's $t$ test or the Mann-Whitney $U$ test. To identify predictors of in-hospital mortality, univariate and multivariate logistic regression analyses were performed with 3 models: model 1 was derived from the overall cohort, model 2 was derived from STEMI patients, and model 3 was derived from NSTEMI patients. Selected variables were advanced age, male gender, systolic blood pressure, heart rate, Killip classification, percutaneous coronary intervention (PCI) of $24 \mathrm{~h}$ from onset, smoking, diabetes mellitus, dyslipidemia treated with statin, hyperuricemia, past MI, history of heart failure (HF), old cerebral infarction $(\mathrm{CI})$, hemodialysis, and history of PCI. Only variables with a $p$ value $\leq 0.05$ identified with univariate analysis were entered as explanatory variables in subsequent multivariate models. All probability values were 2 tailed, and values of $p<0.05$ were considered statistically significant. Statistical analysis was performed using IBM SPSS statistics 20 (IBM corporation, Armonk, NY, USA).

\section{Results}

\section{Patients' demographics}

Clinical patient characteristics are summarized in Table 1. The average age was 68 years old, and $74.6 \%$ were male. Approximately, two-thirds had hypertension, $40 \%$ dyslipidemia, one-third diabetes mellitus, and one-third were current smokers. With regards to location of onset, $67.8 \%$ of patients experienced their first attack at home, $22 \%$ away from home, $5.9 \%$ in a hospital, and $4.2 \%$ were unknown.

When comparing subgroups, NSTEMI patients were typically older than those with STEMI. Moreover, NSTEMI patients were more likely to have history of cardiovascular disease and additional coronary risk factors with the exception to hemodialysis patients, those with dyslipidemia, and/or are current smokers. The distribution of Killip classification and location of onset were statistically similar between the 2 groups. Of the patients with PCI for which time course information was available $(n=3266)$, the median onset-to-door time (the median time interval between the onset of symptom and the patient's hospital arrival) was $180 \mathrm{~min}$. The interval was longer in NSTEMI patients $(n=714)$ than in STEMI patients $(n=2554)$ (median time was 233 vs $165 \mathrm{~min} ; p<0.001$ ). The median door-to-balloon time (the median time interval between the patient's arrival at the hospital and flow restoration by means of balloon inflation) was 60 and $145 \mathrm{~min}$ in STEMI $(n=1969)$ and NSTEMI $(n=432)$, respectively. Of STEMI patients $(n=1969), 68.2 \%(n=1343)$ and $90.5 \%$ $(n=1784)$ underwent primary PCI within $90 \mathrm{~min}$ and $6 \mathrm{~h}$ upon arrival to the hospital, respectively. The appropriateness of primary PCI was analyzed based on US guideline of appropriate use criteria for coronary revascularization [9]. Of STEMI patients, to which primary PCI was available to onset-to-balloon time $(n=1473), 89.4 \%$ of these patients $(n=1318)$ received primary PCI within $12 \mathrm{~h}$ from onset of symptom.

\section{Management and outcome}

Table 2 shows the use of pharmacological therapies during hospitalization. Heparin was administered as an anticoagulant therapy to $87.9 \%$ of patients, whereas, aspirin was prescribed as antiplatelet therapy to $93.6 \%$. Eighty percent of patients who underwent PCI received dual antiplatelet therapy (DAPT) during their admission. Angiotensin-converting enzyme inhibitor (ACEI)/angiotensin II receptor blocker (ARB), $\beta$ blocker, and calcium antagonists 
Table 1 Patients' clinical characteristics

\begin{tabular}{|c|c|c|c|c|}
\hline & Total $(n=4329)$ & STEMI $(n=3202)$ & NSTEMI $(n=1127)$ & $p$ value \\
\hline Age (years) & $67.9 \pm 13.0$ & $67.3 \pm 13.1$ & $69.5 \pm 12.5$ & $<0.001$ \\
\hline Male $(\%)$ & 74.6 & 75.5 & 72.3 & 0.041 \\
\hline BMI $\left(\mathrm{kg} / \mathrm{m}^{2}\right)$ & $23.7 \pm 4.0$ & $23.7 \pm 3.8$ & $23.8 \pm 4.5$ & 0.203 \\
\hline Systolic BP (mmHg) & $134.6 \pm 36.7$ & $133.1 \pm 40.6$ & $140.3 \pm 29.4$ & $<0.001$ \\
\hline HR (beat/min) & $79.5 \pm 21.2$ & $79.0 \pm 21.8$ & $81.0 \pm 19.5$ & 0.014 \\
\hline \multicolumn{5}{|l|}{ Cardiovascular history } \\
\hline MI $(\%)$ & 9.2 & 7.3 & 13.7 & $<0.001$ \\
\hline PCI $(\%)$ & 8.1 & 6.6 & 11.7 & $<0.001$ \\
\hline CABG surgery $(\%)$ & 1.9 & 1.0 & 4.0 & $<0.001$ \\
\hline Heart failure $(\%)$ & 1.7 & 1.3 & 2.6 & 0.017 \\
\hline Cerebral infarction (\%) & 5.7 & 5.3 & 6.7 & 0.118 \\
\hline Hemodialysis $(\%)$ & 3.9 & 2.1 & 8.0 & $<0.001$ \\
\hline $\operatorname{PAD}(\%)$ & 1.5 & 1.3 & 2.2 & 0.064 \\
\hline \multicolumn{5}{|l|}{ Coronary risk factor } \\
\hline Hypertension (\%) & 61.9 & 60.9 & 64.4 & 0.059 \\
\hline Dyslipidemia (\%) & 43.4 & 43.5 & 43.1 & 0.847 \\
\hline Diabetes mellitus (\%) & 32.5 & 31.1 & 36.0 & 0.006 \\
\hline Current smoker (\%) & 32.9 & 34.3 & 29.6 & 0.009 \\
\hline Hyperuricemia (\%) & 5.1 & 5.1 & 5.3 & 0.795 \\
\hline \multicolumn{5}{|l|}{ Location of onset } \\
\hline Home & 67.8 & 66.8 & 70.2 & 0.527 \\
\hline Outside the house & 22.0 & 24.1 & 17.2 & \\
\hline In hospital & 5.9 & 5.2 & 7.7 & \\
\hline Unknown & 4.2 & 3.9 & 4.9 & \\
\hline \multicolumn{5}{|l|}{ Killip classification } \\
\hline Class $1(\%)$ & 74.6 & 74.3 & 75.6 & 0.402 \\
\hline Class $2(\%)$ & 13.4 & 13.2 & 14.0 & \\
\hline Class $3(\%)$ & 5.4 & 4.7 & 7.1 & \\
\hline Class $4(\%)$ & 6.5 & 7.8 & 3.3 & \\
\hline \multicolumn{5}{|l|}{ Time course } \\
\hline Onset-to-Door & $(n=3266)$ & $(n=2554)$ & $(n=714)$ & \\
\hline Median time (min) & 180 & 165 & 233 & $<0.001$ \\
\hline Interquartile range (min) & $80-475$ & $74-423$ & $110-653$ & \\
\hline Door-to-Ballon time & $(n=2401)$ & $(n=1969)$ & $(n=432)$ & \\
\hline Median time (min) & 66 & 60 & 145 & $<0.001$ \\
\hline Interquartile range (min) & $39-130$ & $35-104$ & $61-681$ & \\
\hline
\end{tabular}

STEMI ST-segment elevation myocardial infarction, NSTEMI non-ST-segment elevation myocardial infarction, $B M I$ body mass index, $B P$ blood pressure, $H R$ heart rate, $M I$ myocardial infarction, $P C I$ percutaneous coronary intervention, $C A B G$ coronary artery bypass graft, $P A D$ peripheral artery disease

were prescribed to approximately 60,40 , and $20 \%$ of all patients, respectively. Statin was administered to $65 \%$ of all patients. In-hospital pharmacological therapies were used more frequently in STEMI patients than NSTEMI patient, with the exception of calcium antagonists, where its use was higher in NSTEMI. In STEMI patients, the proportion of thrombolytic therapy including facilitated PCI and thrombolysis alone was just $3.1 \%$ (data not shown).

Angiographic findings, invasive procedures, time courses, and in-hospital deaths are shown in Table 3. Most patients
$(92.2 \%)$ underwent coronary angiography. Culprit lesions included the right coronary artery and the left anterior descending artery in a majority of STEMI patients, whereas culprit lesions involved the left main trunk, left circumflex artery, and undefined lesions appeared more frequently in NSTEMI patients than STEMI patients. Of NSTEMI patients, $55.2 \%$ had multi vessel diseases, and almost the same proportion of STEMI patients $(55.4 \%)$ had single vessel disease. With respect to invasive procedures, $83.5 \%$ of all patients underwent PCI during hospitalization; STEMI 
Table 2 Pharmacological therapies during hospitalization

\begin{tabular}{llllr}
\hline & Total $(n=3241)$ & STEMI $(n=2221)$ & NSTEMI $(n=1020)$ & $p$ value \\
\hline Heparin (\%) & 87.9 & 88.8 & 85.8 & 0.015 \\
Aspirin (\%) & 93.6 & 94.6 & 91.3 & $<0.001$ \\
Thienopyridine (\%) & 73.1 & 77.4 & 63.6 & $<0.001$ \\
DAPT & 71.7 & 76.2 & 62.0 & $<0.001$ \\
PCI with DAPT & 80.7 & 82.1 & 76.6 & 0.002 \\
Statin (\%) & 65.0 & 68.6 & 57.2 & $<0.001$ \\
ACEI/ARB (\%) & 58.3 & 61.5 & 51.4 & $<0.001$ \\
Nitrate (\%) & 44.2 & 44.8 & 42.9 & 0.32 \\
$\beta$ blocker (\%) & 38.8 & 41.7 & 32.5 & $<0.001$ \\
Nicorandil (\%) & 41.5 & 46.0 & 31.7 & $<0.001$ \\
Diuretic (\%) & 23.2 & 23.5 & 22.6 & 0.62 \\
Calcium antagonist (\%) & 17.6 & 15.2 & 22.7 & $<0.001$ \\
Oral antidiabetic drug (\%) & 9.8 & 10.1 & 9.1 & 0.41 \\
Insulin (\%) & 6.5 & 6.2 & 7.4 & 0.22 \\
\hline
\end{tabular}

$D A P T$ dual antiplatelet therapy, $A C E I$ angiotensin-converting enzyme inhibitor, $A R B$ angiotensin receptor blocker

\begin{tabular}{|c|c|c|c|c|}
\hline & Total $(n=4329)$ & STEMI $(n=3202)$ & NSTEMI $(n=1127)$ & $p$ value \\
\hline \multicolumn{5}{|l|}{ Angiographic findings } \\
\hline CAG $(\%)$ & 92.2 & 94.1 & 87.7 & $<0.001$ \\
\hline Culprit lesion & & & & $<0.001$ \\
\hline $\mathrm{RCA}$ & 34.5 & 38.7 & 23.4 & \\
\hline LMT & 3.3 & 2.6 & 5.2 & \\
\hline LAD & 45.2 & 47.8 & 37.9 & \\
\hline LCX & 13.9 & 9.7 & 25.2 & \\
\hline Others & 0.5 & 0.2 & 1.3 & \\
\hline Undefined & 2.6 & 0.9 & 6.9 & \\
\hline The number of diseased vessels & & & & $<0.001$ \\
\hline Single vessel & 52.9 & 55.4 & 44.8 & \\
\hline Multi vessel & 47.1 & 44.6 & 55.2 & \\
\hline \multicolumn{5}{|l|}{ Treatment } \\
\hline PCI (\%) & 83.5 & 88.8 & 70.4 & $<0.001$ \\
\hline PCI within $24 \mathrm{~h}(\%)$ & 73.2 & 81.1 & 53.7 & $<0.001$ \\
\hline Thrombus Aspiration (\%) & 55.1 & 61.9 & 28.3 & $<0.001$ \\
\hline Distal protection device (\%) & 7.5 & 8.1 & 4.8 & 0.006 \\
\hline The type of stent & & & & $<0.001$ \\
\hline BMS & 60.0 & 64.2 & 46.6 & \\
\hline DES & 27.0 & 22.4 & 41.7 & \\
\hline Unknown & 13.0 & 13.4 & 11.7 & \\
\hline CABG $(\%)$ & 6.3 & 4.2 & 11.4 & $<0.001$ \\
\hline IABP & 12.2 & 11.5 & 14.0 & 0.039 \\
\hline PCPS & 3.6 & 4.1 & 1.9 & $<0.001$ \\
\hline \multicolumn{5}{|l|}{ Outcome } \\
\hline In-hospital mortality (\%) & 7.0 & 7.7 & 5.1 & 0.007 \\
\hline
\end{tabular}

$B M S$ bare metal stent, $D E S$ drug eluting stent
Table 3 Angiographic findings, invasive procedures, and in-hospital outcome and NSTEMI patients accounted for 88.8 and $70.4 \%$ of all patients, respectively $(p<0.001)$. Of all patients who underwent PCI, bare metal stents and drug eluting stents were inserted in 60.0 and $27.0 \%$, respectively. Bypass surgery was performed more frequently in NSTEMI patients than STEMI patients (11.4 vs. $4.2 \%$, respectively, $p<0.001)$. 
Table 4 Univariate and multivariate logistic regression analysis

\begin{tabular}{|c|c|c|c|c|}
\hline \multicolumn{5}{|l|}{ AMI patients $(n=2724)$} \\
\hline & \multicolumn{2}{|l|}{ Univariate } & \multicolumn{2}{|l|}{ Multivariate } \\
\hline & Odd ratio $(95 \% \mathrm{CI})$ & $p$ value & Odd ratio $(95 \% \mathrm{CI})$ & $p$ value \\
\hline \multicolumn{5}{|l|}{ Dependent variable; in-hospital mortality } \\
\hline \multicolumn{5}{|l|}{ Independent variable } \\
\hline Age (per 1-year increase) & $1.056(1.045-1.067($ & $<0.001$ & $1.048(1.030-1.066)$ & $<0.001$ \\
\hline Male & $0.631(0.492-0.809)$ & $<0.001$ & $0.744(0.499-1.110)$ & 0.147 \\
\hline Systolic BP (per $10 \mathrm{mmHg}$ increase) & $0.982(0.978-0.987)$ & $<0.001$ & $0.993(0.987-0.998)$ & 0.011 \\
\hline HR (per decile) & $1.173(1.115-1.235)$ & $<0.001$ & $1.073(1.009-1.142)$ & 0.025 \\
\hline STEMI & $1.555(1.156-2.092)$ & 0.004 & $1.582(0.980-2.558)$ & 0.060 \\
\hline Killip & $3.019(2.713-3.359)$ & $<0.001$ & $2.515(2.155-2.936)$ & $<0.001$ \\
\hline PCI within $24 \mathrm{~h}$ & $0.462(0.363-0.589)$ & $<0.001$ & $1.073(1.009-1.142)$ & 0.144 \\
\hline Smoking & $0.424(0.309-0.582)$ & $<0.001$ & $0.954(0.613-1.482)$ & 0.833 \\
\hline Diabetes mellitus & $1.243(0.961-1.609)$ & 0.097 & & \\
\hline Dyslipidemia treated with statin (reference; no dyslipidemia) & $0.236(0.161-0.346)$ & $<0.001$ & $0.365(0.223-0.596)$ & 0.045 \\
\hline Hyperuricemia & $1.240(0.732-2.101)$ & 0.424 & & \\
\hline Prior MI & $1.805(1.256-2.594)$ & 0.001 & $1.447(0.818-2.560)$ & 0.205 \\
\hline History of heart failure & $2.769(1.432-5.355)$ & 0.002 & $0.994(0.405-2.445)$ & 0.990 \\
\hline Old cerebral infarction & $2.045(1.347-3.104)$ & 0.001 & $1.169(0.631-2.168)$ & 0.619 \\
\hline Hemodialysis & $2.496(1.542-4.040)$ & $<0.001$ & $2.294(1.107-4.753)$ & 0.026 \\
\hline History of PCI & $1.507(1.028-2.209)$ & 0.036 & $1.346(0.743-2.445)$ & 0.327 \\
\hline
\end{tabular}

Statistical significant values $(p<0.05)$ in multivariate analysis are highlighted in bold

STEMI patients had significantly a higher in-hospital mortality rate than NSTEMI patients ( 7.5 vs. $5.1 \%$, $p=0.007$ ) (Table 4).

\section{Multivariate analysis}

After logistic regression analysis, independent prognosticators of in-hospital mortality in STEMI patients were: advanced age, low blood pressure, and high Killip classification; whereas statin-treated dyslipidemia and PCI performed within $24 \mathrm{~h}$ from onset were associated lower risk of death (Table 5). For NSTEMI patients, independent prognosticators of in-hospital mortality were: high heart rate, high Killip classification, and hemodialysis (Table 6); whereas statin-treated dyslipidemia was the only factor associated with lowering risk of death. Independent predictors of in-hospital mortality in AMI patients were very comparable to prognosticators for STEMI and NSTEMI (Table 4). Killip classification was the strongest predictor of in-hospital mortality in all groups. Since statin-treated dyslipidemia was associated with lowering risk of death, we compared patients with statin-treated dyslipidemia to patients without dyslipidemia. STEMI patient with statin-treated dyslipidemia had more Killip 1 than patients without dyslipidemia, however, this was not the case in NSTEMI patients. More frequently than patients without dyslipidemia, both STEMI and NSTEMI patients with stain-treated dyslipidemia received PCI within $24 \mathrm{~h}$. Door-to-balloon time was similar between cases with stain-treated dyslipidemia and without dyslipidemia in both STEMI and NSTEMI patients. Excluding history of cerebral infarction, the history of cardiovascular disease and coronary risk factors were similar among cases with stain-treated dyslipidemia and without dyslipidemia in STEMI and NSTEMI patients. Cases without dyslipidemia had more history of cerebral infarction than cases with stain-treated dyslipidemia in both STEMI and NSTEMI patients groups (data not shown).

\section{Discussion}

To the best of our knowledge, the Tokyo CCU network is the largest citywide, most well-organized cardiac care system for a metropolitan city area in the world. This citywide, multicenter, prospective observational registry provides insight on the characteristics, management, and in-hospital mortality rates of both STEMI and NSTEMI patients. NSTEMI patients tended to have more extensive medical histories, including more cardiovascular events and coronary risk factors, than STEMI patients. Nevertheless, NSTEMI patients tended to receive in-hospital 
Table 5 Univariate and multivariate logistic regression analysis

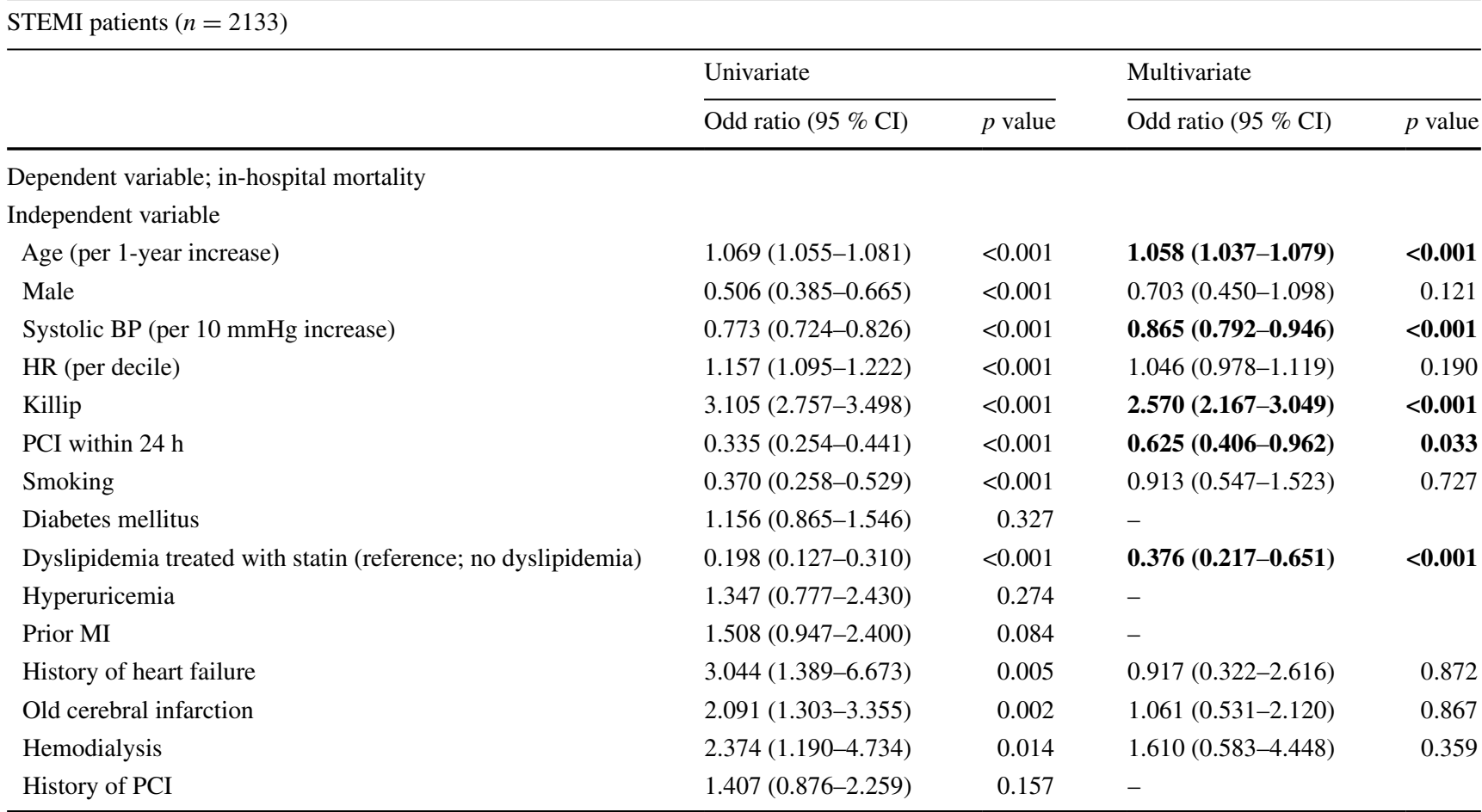

Statistical significant values $(p<0.05)$ in multivariate analysis are highlighted in bold

Table 6 Univariate and multivariate logistic regression analysis

\begin{tabular}{|c|c|c|c|c|}
\hline \multicolumn{5}{|l|}{ NSTEMI patients $(n=646)$} \\
\hline & \multicolumn{2}{|l|}{ Univariate } & \multicolumn{2}{|l|}{ Multivariate } \\
\hline & Odd ratio $(95 \% \mathrm{CI})$ & $p$ value & Odd ratio $(95 \% \mathrm{CI})$ & $p$ value \\
\hline \multicolumn{5}{|l|}{ Dependent variable; in-hospital mortality } \\
\hline \multicolumn{5}{|l|}{ Independent variable } \\
\hline Age (per 1-year increase) & $1.015(0.993-1.038)$ & 0.182 & - & \\
\hline Male & $1.637(0.837-3.203)$ & 0.150 & - & \\
\hline Systolic BP (per 10 mmHg increase) & $0.973(0.850-1.113)$ & 0.688 & - & \\
\hline HR (per decile) & $1.290(1.123-1.482)$ & $<0.001$ & $1.165(1.012-1.342)$ & 0.034 \\
\hline Killip & $2.617(2.045-3.348)$ & $<0.001$ & $2.420(1.727-3.392)$ & $<0.001$ \\
\hline PCI within $24 \mathrm{~h}$ & $0.728(0.416-1.274)$ & 0.267 & - & \\
\hline Smoking & $0.695(0.349-1.383)$ & 0.300 & - & \\
\hline Diabetes mellitus & $1.833(1.025-3.280)$ & 0.041 & $1.205(0.550-2.641)$ & 0.641 \\
\hline Dyslipidemia treated with statin (reference; no dyslipidemia) & $0.415(0.194-0.887)$ & 0.023 & $0.368(0.139-0.977)$ & 0.045 \\
\hline Hyperuricemia & $0.771(0.182-3.270)$ & 0.724 & - & \\
\hline Prior MI & $3.390(1.805-6.368)$ & $<0.001$ & $1.691(0.638-4.485)$ & 1.691 \\
\hline History of heart failure & $2.715(0.783-9.410)$ & 0.115 & - & \\
\hline Old cerebral infarction & $2.080(0.850-5.091)$ & 0.109 & - & \\
\hline Hemodialysis & $3.838(1.872-7.870)$ & $<0.001$ & $3.627(1.326-9.920)$ & 0.012 \\
\hline History of PCI & $2.217(1.122-4.379)$ & 0.022 & $1.582(0.585-4.275)$ & 0.366 \\
\hline
\end{tabular}

Statistical significant values $(p<0.05)$ in multivariate analysis are highlighted in bold 
pharmacological therapies and undergo PCI less frequently than STEMI patients. These tendencies are not unique to Tokyo CCU network and are similar to many registries in Japan and other countries [10-12].

For this study, we focused on the comparing in-hospital mortality with previous studies performed in other countries. In the other studies, the in-hospital mortality rate was $4.6-8.9 \%$ in STEMI and 4.2-5.8 \% in NSTEMI [11-14], thus our results are comparable to other various large and/or small-scale registries. However, the approach to the management of coronary revascularization in Japan is unique and comparisons made between the Tokyo CCU network and foreign registries are unreliable. Therefore, we compared our data with the most notable registry in Japan, namely, the Prevention of AtherothrombotiC Incidents Following Ischemic Coronary attack (PACIFIC) registry. The PACIFIC registry is comprised of 96 Japanese regional core hospitals, that have the facilities for advanced interventional therapy, participating in a large-scale, prospective observational study [10]. In the PACIFIC registry, in-hospital mortality for STEMI and non-ST elevation acute coronary syndrome (which includes NSTEMI and unstable angina) was 4.1 and $1.3 \%$, respectively. The PACIFIC registry data was characterized by a high proportion of patients of who received PCI (93.5\%) and low proportions of Killip class 3 and 4 (2.9 and $2.8 \%$, respectively), which contrasts with the present study. Whereas, all participating PACIFIC registry hospitals were regional core hospitals and had facilities for advanced interventional therapy, Tokyo CCU network hospitals have varying degrees of different capabilities. Roughly $30 \%$ of Tokyo CCU network hospitals have fewer than 4 beds in the $\mathrm{CCU}$, are incapable of performing emergency cardiovascular surgery, and come across less than 200 PCIs annually. Generally, to perform PCI, many Japanese hospitals with a cardiology unit have their own catheterization laboratories. Accordingly, primary PCI is performed in what may be considered relatively small-scale hospitals. In terms of hospital size and capability, we believe that our registry reflects more closely the real-world clinical data of a Japanese metropoli$\tan$ area. Of particular note, there was a higher proportion of NSTEMI patients with hemodialysis $(8.0 \%)$ for this study. It is known that Japan has one of the highest hemodialysis rates when compared with elsewhere in the world $[15,16]$, and correspondingly patients with chronic kidney disease on hemodialysis have higher rates of cardiovascular morbidity and mortality [17].

With regards to onset-to-door times, there are two main components that may potentially cause delays; the pre-hospital patient decision delay and pre-hospital transportation delay [18]. According to several studies about patient delay in Europe and the US, it remains a controversial topic whether education campaigns significantly contribute to delay reductions from onset to hospital arrival [19-21]. Furthermore, the pre-hospital transportation delay depends largely on the emergency medical service response time in Tokyo. The median time interval from first medical contact to hospital presentation was $37 \mathrm{~min}$ in the Tokyo CCU network (data not shown as table). This time interval is acceptable, but streamlining the process of hospital selection may be needed.

With regards to pharmacological therapies, $\beta$ blocker was prescribed to fewer patients in comparison to the French OPERA registry [12]. However, $\beta$ blocker utilization rates in Japan are generally lower than that of Western countries, even though favorable $\beta$ blocker effects on AMI have been reported [22-25]. The plausible explanation for lower $\beta$ blocker utilization is that the cardiovascular event rate after AMI for Japanese patients is lower than that of Western patients and coronary spasm incidences for Japanese patients is higher than that of Western patients [26]. Nicorandil utilization rates were extremely high in this study (44.2\%). The J-wind study in Japan showed that nicorandil had a favorable effect for acute MI patients and improved the left ventricular ejection fraction even though it did not reduce infarct size or the incidence of cardiac death [27]. Consequently, there factors may affect the selection of medications.

Multivariate logistic regression analysis showed that statin-treated dyslipidemia was associated with lower risk in both STEMI and NSTEMI patients. These findings lend further support to the effectiveness of statin treatment in STEMI and NSTEMI [28, 29]. Additionally, PCI performed within 24-h was associated with lower in-hospital mortality rates in STEMI patients. It is well established that primary PCI is greatly beneficial for STEMI [1, 2]. In contrast, the optimal intervention time for the treatment of NSTEMI patients has been debated for years [30-32]. Several randomized trials have shown that in NSTEMI patients, an early-intervention strategy was not superior to a delayed-intervention strategy for the prevention of death $[31,32]$. On the other hand, recent updated guidelines for NSTEMI recommended an early invasive strategy within 24-h for high-risk patients defined as GRACE score of $>140$ [3, 4]. In this study's NSTEMI data, there was no statistical superiority between survival rates for PCI performed within 24-h versus PCI performed after $24 \mathrm{~h}$. A reason for our findings in multivariate logistic regression is the inclusion of all patients, but not selected patients.

These study findings have clinical implications and can provide much information to cardiologists. At the level of statistical significance, the second strongest predictor of inhospital mortality was hemodialysis in NSTEMI patients. Therefore, cardiologists and nephrologists must pay greater attention in cases involving the cardiovascular events of patients with hemodialysis.

Furthermore, current STEMI guidelines recommend a door-to-balloon time of $90 \mathrm{~min}$ or less for patients 
undergoing primary PCI $[2,33]$. Door-to-balloon time in this study was shorter than that of recommended guidelines, and approximately $70 \%$ of patients were prepared to undergo primary PCI within 90 min upon arrival to the hospital. Moreover, according to US guidelines of appropriate use criteria [9], coronary revascularization is appropriate $12 \mathrm{~h}$ or less from the onset of symptoms for STEMI patients. For this study, $89.4 \%$ of patients were appropriately eligible to receive primary PCI based on US guideline of appropriate use criteria for coronary revascularization. Thus the promptness and appropriateness of primary PCI were within acceptable parameters. Nevertheless, in-hospital mortality in this study was not particularly low. Approaches with the potential to improve in-hospital mortality may include reducing the number of patients with door-to-balloon times greater than $90 \mathrm{~min}$, increasing the patients' awareness of symptoms, and shorting the transfer time between first medical contact and hospital presentation.

\section{Limitations}

The present study is subject to some intrinsic limitations associated with an observational study. Patients that did not need to be hospitalized in the $\mathrm{CCU}$ were not registered in this study, therefore, low-risk patients may have been excluded. Since we redefined the STEMI and NSTEMI as troponin $\mathrm{T}>0.1 \mathrm{ng} / \mathrm{ml}$ in this study, there were some unavailable and missing data for each patient existed. Of 962 patients who were excluded, $63.5 \%$ were not described as having STEMI or NSTEMI. A proportion of excluded patients underwent PCI within $24 \mathrm{~h}$ upon arrival to the hospital were lower than those of study patients $(68.8$ vs. $73.2 \%, p=0.06$ ). The distribution of Killip class for excluded patients was markedly different from those of study patients $(1,69.0 \% ; 2,13.4 \% ; 3,7.6 \% ; 4,10.0 \%$; $p=0.010)$. In-hospital mortality rate of excluded patients was higher than that of study patients (10.9 vs. $7.0 \%$, $p<0.001$ ). Therefore, severe patient cases may have been excluded, and selection bias may have affected the results. Moreover, the number of registered patients varied widely among hospitals. Thus, large institutional variations may have occurred. In addition, important pieces of information such as long-term outcomes and events, left ventricular ejection fraction (LVEF), medication doses, and the initiation times of medications were not assessed in the present study. Within the present study, we showed that statin-treated dyslipidemia was associated with a lower risk of in-hospital mortality when compared to patients with no dyslipidemia. However, it remains unknown whether the effect was due to early or continuing statin treatment. Though it is important to describe in detail ST-segment change (ST-segment elevation, left bundle branch block, ST-segment depression, or T-wave inversion), details of ST-segment change were not evaluated in this study. Moreover, the usage rate of drug eluting stent (DES) was low in this study. In 2009-2010, many cardiologists recognized that the stent thrombosis rate of firstgeneration DES was increasing year by year [34-36]. The second generation of DES (such as the Everolimus-eluting stent) was released in Japan in 2010. Thus, many cardiologists may have avoided implanting DES to AMI patients due to these reasons.

Despite these limitations, we believe that our findings regarding acute situations in MI patients are accurate reflections within the contemporary DES and Troponin era in Tokyo.

\section{Conclusions}

This metropolitan observational study revealed that STEMI and NSTEMI patients have different characteristics, managements, and prognoses. Compared with NSTEMI patient, those with STEMI generally have shorter door-to-balloon times, a higher proportion of PCI, more optimal medical therapy, but higher in-hospital mortality rates. In addition to the traditional negative independent predictors of in-hospital mortality such as age or Killip Classification, PCI performed within $24 \mathrm{~h}$ from onset and statin-treated dyslipidemia were positively associated with favorable in-hospital outcomes in STEMI patients. In contrast, for NSTEMI patients, PCI performed within $24 \mathrm{~h}$ from onset was proved to be the only positive factor to lower risk of in-hospital mortality. Moreover, in addition to the negative STEMI predictors, hemodialysis was found to be another an independent correlates of in-hospital mortality in NSTEMI patients.

Acknowledgments We thank all the cardiologists and staff participating in the Tokyo CCU network and Mrs. Nobuko Yoshida (Tokyo CCU network office) for data acquisition. All hospitals and leading members participating in the Tokyo CCU network are listed in "Appendix".

Compliance with ethical standards All procedures performed in the study involving human participants were in accordance with the ethical standards of each institutional research committee and with the 1964 Helsinki declaration and its later amendments or comparable ethical standards.

Conflict of interest The authors declare that they have no conflict of interest.

Open Access This article is distributed under the terms of the Creative Commons Attribution 4.0 International License (http://creativecommons.org/licenses/by/4.0/), which permits unrestricted use, distribution, and reproduction in any medium, provided you give appropriate credit to the original author(s) and the source, provide a link to the Creative Commons license, and indicate if changes were made. 


\section{Appendix: Author contributions}

Ayase Heart Hospital, Imun Tei; Bokutoh Metropolitan General Hospital, Ichiro Kubo; Disaster Medical Center, Yasuhiro Satoh; Edogawa Hospital, Yoji Oohira; Hakujikai Memorial Hospital, Kunio Tanaka; Higashiyamato Hospital, Masao Kawada; Ikegami General Hospital, Takao Machimura; IMS Katsushika Heart Center, Shigehiko Yoshida; Itabashi Chuo Medical Center, Hiroshi Ota; Japanese Red Cross Medical Center, Hiroshi Ikenouchi; Jikei University Daisan Hospital, Takahiro Shibata; Jikei University Hospital Katsushika Medical Center, Shingo Seki; Juntendo University Hospital, Hiroyuki Daita; Kanto Central Hospital, Akira Nozaki; Kanto Medical Center NTT EC, Satoshi Onishi; Kasai Shoikai Hospital, Akihiro Hata; Kawakita General Hospital, Yoichi Sugimura; Keio University Hospital, Tsutomu Yoshikawa; Kohsei Chuo Hospital, Akio Hirai; Kosei General Hospital, Masao Kawaguchi; Kyorin University Hospital, Hideo Yoshino; Mishuku Hospital, Akimi Uehata; Mitsui Memorial Hospital, Kazuhiro Hara; Musashino Red Cross Hospital, Tohru Obayashi; National Center for Global Health and Medicine, Hisao Hara; National Hospital Organization, Tokyo Medical Center, Yukihiko Momiyama; Nihon University Itabashi Hospital, Tadateru Takayama; Nihon University Nerima Hikarigaoka Hospital, Seiji Fukushima; Nippon Medical School Hospital, Keiji Tanaka; Nippon Medical School Tama-Nagayama Hospital, Hirotsugu Atarashi; Nishiarai Heart Center Hospital, Katsumi Saito; Nishitokyo Central General Hospital, Hiroyuki Suesada; Ogikubo Hospital, Yasuhiro Ishii; Ome Municipal General Hospital, Shigeo Shimizu; Saiseikai Central Hospital, Hideo Mitamura; Sakakibara Heart Institute, Tetsuya Sumiyoshi; Senpo Tokyo Takanawa Hospital, Masato Yamamoto; Showa General Hospital, Yuji Kira; Showa University Hospital, Youichi Kobayashi; Social Insurance Central General Hospital, Makoto Noda; St. Luke's International Hospital, Yutaro Nishi; Surugadai Nihon University Hospital, Ken Nagao; Tama Nambu Chiiki Hospital, Tatenori Suzuki; Tama-Hokubu Medical Center, Satoshi Murasaki; Teikyo University Hospital, Takaaki Isshiki; The Cardiovascular Institute, Akira Koike; The Jikei University Hospital, Michihiro Yoshimura; The University of Tokyo Hospital, Ryozo Nagai; Tobu Chiiki Hospital, Takashi Tamura; Toho University Omori Medical Center, Nobuya Koyama; Toho University, Ohashi Medical Center, Masato Nakamura; Tokai University Hachioji-Hospital, Yoshinori Kobayashi; Tokyo Heart Center, Joji Hosokawa; Tokyo Kosei Nenkin Hospital, Seiji Ayabe; Tokyo Medical and Dental University, Mitsuaki Isobe; Tokyo Medical University, Hachioji Medical Center, Hiroshi Kobayashi; Tokyo Medical University Hospital, Akira Yamashina; Tokyo Metropolitan
Geriatric Hospital, Kazumasa Harada; Tokyo Metropolitan Hiroo Hospital, Harumizu Sakurada; Tokyo Metropolitan Police Hospital, Tetsuro Shirai; Tokyo Metropolitan Tama Medical Center, Tetsuro Ueda; Tokyo Rinkai Hospital, Toru Kohno; Tokyo Women's Medical University Hospital, Nobuhisa Hagiwara; Tokyo Women's Medical University Medical Center East, Kuniaki Otsuka; Tokyo-kita Social Insurance Hospital, Yoshio Tsuruya; Toranomon Hospital, Sugao Ishiwata; Toshima Hospital, Takashi Shibui (67 hospitals).

\section{References}

1. Cannon CP, Gibson CM, Lambrew CT, Shoultz DA, Levy D, French WJ, Gore JM, Weaver WD, Rogers WJ, Tiefenbrunn AJ (2000) Relationship of symptom-onset-to-balloon time and doorto-balloon time with mortality in patients undergoing angioplasty for acute myocardial infarction. JAMA 283:2941-2947

2. O'Gara PT, Kushner FG, Ascheim DD, Casey DE Jr, Chung MK, de Lemos JA, Ettinger SM, Fang JC, Fesmire FM, Franklin BA, Granger CB, Krumholz HM, Linderbaum JA, Morrow DA, Newby LK, Ornato JP, Ou N, Radford MJ, Tamis-Holland JE, Tommaso CL, Tracy CM, Woo YJ, Zhao DX, Anderson JL, Jacobs AK, Halperin JL, Albert NM, Brindis RG, Creager MA, DeMets D, Guyton RA, Hochman JS, Kovacs RJ, Ohman EM, Stevenson WG, Yancy CW (2013) 2013 ACCF/AHA guideline for the management of ST-elevation myocardial infarction: a report of the American College of Cardiology Foundation/American Heart Association Task Force on Practice Guidelines. Circulation 127:e362-e425

3. Jneid H, Anderson JL, Wright RS, Adams CD, Bridges CR, Casey DE Jr, Ettinger SM, Fesmire FM, Ganiats TG, Lincoff AM, Peterson ED, Philippides GJ, Theroux P, Wenger NK, Zidar JP (2012) 2012 ACCF/AHA focused update of the guideline for the management of patients with unstable angina/NonST-elevation myocardial infarction (updating the 2007 guideline and replacing the 2011 focused update): a report of the American College of Cardiology Foundation/American Heart Association Task Force on practice guidelines. Circulation 126:875-910

4. Hamm CW, Bassand JP, Agewall S, Bax J, Boersma E, Bueno H, Caso P, Dudek D, Gielen S, Huber K, Ohman M, Petrie MC, Sonntag F, Uva MS, Storey RF, Wijns W, Zahger D (2011) ESC Guidelines for the management of acute coronary syndromes in patients presenting without persistent ST-segment elevation: the Task Force for the management of acute coronary syndromes (ACS) in patients presenting without persistent ST-segment elevation of the European Society of Cardiology (ESC). Eur Heart J 32:2999-3054

5. Takano T, Ida T, Tanaka K, Obayashi K, Kimura E (1981) Prehospital care (CCU network) of acute myocardial infarction and treatment of cardiogenic shock by intra-aortic balloon pumping. Jpn Circ J 45:623-635

6. Network TC (2010) Latest management and outcomes of major pulmonary embolism in the cardiovascular disease early transport system: Tokyo CCU Network. Circ J 74:289-293

7. Takahashi M, Kohsaka S, Miyata H, Yoshikawa T, Takagi A, Harada K, Miyamoto T, Sakai T, Nagao K, Sato N, Takayama M (2011) Association between prehospital time interval and short-term outcome in acute heart failure patients. J Card Fail 17:742-747 
8. Thygesen K, Alpert JS, White HD (2007) Universal definition of myocardial infarction. Eur Heart J 28:2525-2538

9. Patel MR, Dehmer GJ, Hirshfeld JW, Smith PK, Spertus JA (2012) ACCF/SCAI/STS/AATS/AHA/ASNC/HFSA/SCCT 2012 Appropriate use criteria for coronary revascularization focused update: a report of the American College of Cardiology Foundation Appropriate Use Criteria Task Force, Society for Cardiovascular Angiography and Interventions, Society of Thoracic Surgeons, American Association for Thoracic Surgery, American Heart Association, American Society of Nuclear Cardiology, and the Society of Cardiovascular Computed Tomography. J Am Coll Cardiol 59:857-881

10. Daida H, Miyauchi K, Ogawa H, Yokoi H, Matsumoto M, Kitakaze M, Kimura T, Matsubara T, Ikari Y, Kimura K, Tsukahara K, Origasa H, Morino Y, Tsutsui H, Kobayashi M, Isshiki T (2013) Management and two-year long-term clinical outcome of acute coronary syndrome in Japan: prevention of atherothrombotic incidents following ischemic coronary attack (PACIFIC) registry. Circ J 77:934-943

11. Goldberg RJ, Currie K, White K, Brieger D, Steg PG, Goodman SG, Dabbous O, Fox KA, Gore JM (2004) Six-month outcomes in a multinational registry of patients hospitalized with an acute coronary syndrome (the Global Registry of Acute Coronary Events [GRACE]). Am J Cardiol 93:288-293

12. Montalescot G, Dallongeville J, Van Belle E, Rouanet S, Baulac C, Degrandsart A, Vicaut E (2007) STEMI and NSTEMI: are they so different? 1 year outcomes in acute myocardial infarction as defined by the ESC/ACC definition (the OPERA registry). Eur Heart J 28:1409-1417

13. Balzi D, Di Bari M, Barchielli A, Ballo P, Carrabba N, Cordisco A, Landini MC, Santoro GM, Valente S, Zuppiroli A, Marchionni N, Gensini GF (2013) Should we improve the management of NSTEMI? Results from the population-based "acute myocardial infarction in Florence 2" (AMI-Florence 2) registry. Intern Emerg Med 8(8):725-733

14. Ishihara M, Fujino M, Ogawa H, Yasuda S, Noguchi T, Nakao K, Ozaki Y, Kimura K, Suwa S, Fujimoto K, Nakama Y, Morita T, Shimizu W, Saito Y, Tsujita K, Nishimura K, Miyamoto Y (2015) Clinical presentation, management and outcome of Japanese patients with acute myocardial infarction in the troponin eraJapanese registry of acute myocardial infarction diagnosed by universal definition (J-MINUET). Circ J 79:1255-1262

15. Foley RN, Collins AJ (2013) The USRDS: what you need to know about what it can and can't tell us about ESRD. Clin J Am Soc Nephrol 8:845-851

16. Nakai S, Iseki K, Itami N, Ogata S, Kazama JJ, Kimata N, Shigematsu T, Shinoda T, Shoji T, Suzuki K, Taniguchi M, Tsuchida K, Nakamoto H, Nishi H, Hashimoto S, Hasegawa T, Hanafusa N, Hamano T, Fujii N, Masakane I, Marubayashi S, Morita O, Yamagata K, Wakai K, Wada A, Watanabe Y, Tsubakihara Y (2012) An overview of regular dialysis treatment in Japan (as of 31 December 2010). Ther Apher Dial 16:483-521

17. Levey AS, Atkins R, Coresh J, Cohen EP, Collins AJ, Eckardt KU, Nahas ME, Jaber BL, Jadoul M, Levin A, Powe NR, Rossert J, Wheeler DC, Lameire N, Eknoyan G (2007) Chronic kidney disease as a global public health problem: approaches and initiatives-a position statement from kidney disease improving global outcomes. Kidney Int 72:247-259

18. Huber K, De Caterina R, Kristensen SD, Verheugt FW, Montalescot G, Maestro LB, Van de Werf F (2005) Pre-hospital reperfusion therapy: a strategy to improve therapeutic outcome in patients with ST-elevation myocardial infarction. Eur Heart J 26:2063-2074

19. Gaspoz JM, Unger PF, Urban P, Chevrolet JC, Rutishauser W, Lovis C, Goldman L, Heliot C, Sechaud L, Mischler S, Waldvogel FA (1996) Impact of a public campaign on pre-hospital delay in patients reporting chest pain. Heart 76:150-155
20. Herlitz J, Blohm M, Hartford M, Karlson BW, Luepker R, Holmberg S, Risenfors M, Wennerblom B (1992) Follow-up of a 1-year media campaign on delay times and ambulance use in suspected acute myocardial infarction. Eur Heart J 13:171-177

21. Luepker RV, Raczynski JM, Osganian S, Goldberg RJ, Finnegan JR Jr, Hedges JR, Goff DC Jr, Eisenberg MS, Zapka JG, Feldman HA, Labarthe DR, McGovern PG, Cornell CE, Proschan MA, Simons-Morton DG (2000) Effect of a community intervention on patient delay and emergency medical service use in acute coronary heart disease: the rapid early action for coronary treatment (REACT) trial. JAMA 284:60-67

22. ISIS-1 (First International Study of Infarct Survival) Collaborative Group (1986) Randomised trial of intravenous atenolol among 16027 cases of suspected acute myocardial infarction. Lancet 2:57-66

23. JCS Joint Working Group (2013) Guidelines for secondary prevention of myocardial infarction (JCS 2011). Circ J 77:231-248

24. Konishi H, Miyauchi K, Kasai T, Tsuboi S, Ogita M, Naito R, Nishizaki Y, Okai I, Tamura H, Okazaki S, Isoda K, Daida H (2015) Long-term effect of beta-blocker in ST-segment elevation myocardial infarction in patients with preserved left ventricular systolic function: a propensity analysis. Heart Vessels. doi:10.1007/s00380-014-0624-2

25. Hioki H, Motoki H, Izawa A, Kashima $Y$, Miura T, Ebisawa S, Tomita T, Miyashita Y, Koyama J, Ikeda U (2015) Impact of oral beta-blocker therapy on mortality after primary percutaneous coronary intervention for Killip class 1 myocardial infarction. Heart Vessels. doi:10.1007/s00380-015-0673-1

26. Japanese beta-Blockers and Calcium Antagonists Myocardial Infarction (JBCMI) Investigators. (2004) Comparison of the effects of beta blockers and calcium antagonists on cardiovascular events after acute myocardial infarction in Japanese subjects. Am J Cardiol 93:969-973

27. Kitakaze M, Asakura M, Kim J, Shintani Y, Asanuma H, Hamasaki T, Seguchi O, Myoishi M, Minamino T, Ohara T, Nagai Y, Nanto S, Watanabe K, Fukuzawa S, Hirayama A, Nakamura N, Kimura K, Fujii K, Ishihara M, Saito Y, Tomoike H, Kitamura S (2007) Human atrial natriuretic peptide and nicorandil as adjuncts to reperfusion treatment for acute myocardial infarction (J-WIND): two randomised trials. Lancet 370:1483-1493

28. Patti G, Pasceri V, Colonna G, Miglionico M, Fischetti D, Sardella G, Montinaro A, Di Sciascio G (2007) Atorvastatin pretreatment improves outcomes in patients with acute coronary syndromes undergoing early percutaneous coronary intervention: results of the ARMYDA-ACS randomized trial. J Am Coll Cardiol 49:1272-1278

29. Briel M, Schwartz GG, Thompson PL, de Lemos JA, Blazing MA, van Es GA, Kayikcioglu M, Arntz HR, den Hartog FR, Veeger NJ, Colivicchi F, Dupuis J, Okazaki S, Wright RS, Bucher HC, Nordmann AJ (2006) Effects of early treatment with statins on short-term clinical outcomes in acute coronary syndromes: a meta-analysis of randomized controlled trials. JAMA 295:2046-2056

30. Neumann FJ, Kastrati A, Pogatsa-Murray G, Mehilli J, Bollwein H, Bestehorn HP, Schmitt C, Seyfarth M, Dirschinger J, Schomig A (2003) Evaluation of prolonged antithrombotic pretreatment ("cooling-off" strategy) before intervention in patients with unstable coronary syndromes: a randomized controlled trial. JAMA 290:1593-1599

31. Mehta SR, Granger CB, Boden WE, Steg PG, Bassand JP, Faxon DP, Afzal R, Chrolavicius S, Jolly SS, Widimsky P, Avezum A, Rupprecht HJ, Zhu J, Col J, Natarajan MK, Horsman C, Fox KA, Yusuf S (2009) Early versus delayed invasive intervention in acute coronary syndromes. N Engl J Med 360:2165-2175

32. Montalescot G, Cayla G, Collet JP, Elhadad S, Beygui F, Le Breton H, Choussat R, Leclercq F, Silvain J, Duclos F, Aout M, 
Dubois-Rande JL, Barthelemy O, Ducrocq G, Bellemain-Appaix A, Payot L, Steg PG, Henry P, Spaulding C, Vicaut E (2009) Immediate vs delayed intervention for acute coronary syndromes: a randomized clinical trial. JAMA 302:947-954

33. Steg PG, James SK, Atar D, Badano LP, Blomstrom-Lundqvist C, Borger MA, Di Mario C, Dickstein K, Ducrocq G, FernandezAviles F, Gershlick AH, Giannuzzi P, Halvorsen S, Huber K, Juni P, Kastrati A, Knuuti J, Lenzen MJ, Mahaffey KW, Valgimigli M, van 't Hof A, Widimsky P, Zahger D (2012) ESC Guidelines for the management of acute myocardial infarction in patients presenting with ST-segment elevation. Eur Heart J 33:2569-2619

34. Daemen J, Wenaweser P, Tsuchida K, Abrecht L, Vaina S, Morger C, Kukreja N, Juni P, Sianos G, Hellige G, van Domburg RT, Hess OM, Boersma E, Meier B, Windecker S, Serruys PW (2007) Early and late coronary stent thrombosis of sirolimus-eluting and paclitaxel-eluting stents in routine clinical practice: data from a large two-institutional cohort study. Lancet 369:667-678

35. Kimura T, Morimoto T, Nakagawa Y, Tamura T, Kadota K, Yasumoto $\mathrm{H}$, Nishikawa $\mathrm{H}$, Hiasa Y, Muramatsu T, Meguro T, Inoue N, Honda H, Hayashi Y, Miyazaki S, Oshima S, Honda T, Shiode N, Namura M, Sone T, Nobuyoshi M, Kita T, Mitsudo K (2009) Antiplatelet therapy and stent thrombosis after sirolimus-eluting stent implantation. Circulation 119:987-995

36. Pinto Slottow TL, Steinberg DH, Roy PK, Buch AN, Okabe T, Xue Z, Kaneshige K, Torguson R, Lindsay J, Pichard AD, Satler LF, Suddath WO, Kent KM, Waksman R (2008) Observations and outcomes of definite and probable drug-eluting stent thrombosis seen at a single hospital in a four-year period. Am J Cardiol 102:298-303 